\title{
New Pharmacological Tools to Target Leukocyte Trafficking in Lung Disease
}

\author{
Kylie B. R. Belchamber ${ }^{1 *}$, Michael J. Hughes ${ }^{1}$, Daniella A. Spittle ${ }^{1}$, Eloise M. Walker ${ }^{1}$ \\ and Elizabeth Sapey ${ }^{1,2}$

\begin{abstract}
${ }^{1}$ Birmingham Acute Care Research Group, Institute of Inflammation and Ageing, University of Birmingham, Birmingham, United Kingdom, ${ }^{2}$ NIHR Clinical Research Facility Birmingham, University Hospitals Birmingham NHS Foundation Trust,
\end{abstract} \\ Birmingham, United Kingdom
}

OPEN ACCESS

Edited by:

Emmanuel Donnadieu,

Institut National de la Santé et de la

Recherche Médicale (INSERM),

France

Reviewed by:

Anja Meissner,

Lund University, Sweden

loannis Mitroulis,

Democritus University of Thrace,

Greece

*Correspondence:

Kylie B. R. Belchamber

k.belchamber@bham.ac.uk

Specialty section: This article was submitted to Molecular Innate Immunity, a section of the journal

Frontiers in Immunology

Received: 01 May 2021 Accepted: 24 June 2021

Published: 21 July 2021

Citation:

Belchamber KBR, Hughes MJ, Spittle DA, Walker EM and Sapey E (2021) New Pharmacological Tools

to Target Leukocyte Trafficking in Lung Disease.

Front. Immunol. 12:704173. doi: 10.3389/fimmu.2021.704173
Infection and inflammation of the lung results in the recruitment of non-resident immune cells, including neutrophils, eosinophils and monocytes. This swift response should ensure clearance of the threat and resolution of stimuli which drive inflammation. However, once the threat is subdued this influx of immune cells should be followed by clearance of recruited cells through apoptosis and subsequent efferocytosis, expectoration or retrograde migration back into the circulation. This cycle of cell recruitment, containment of threat and then clearance of immune cells and repair is held in exquisite balance to limit host damage. Advanced age is often associated with detrimental changes to the balance described above. Cellular functions are altered including a reduced ability to traffic accurately towards inflammation, a reduced ability to clear pathogens and sustained inflammation. These changes, seen with age, are heightened in lung disease, and most chronic and acute lung diseases are associated with an exaggerated influx of immune cells, such as neutrophils, to the airways as well as considerable inflammation. Indeed, across many lung diseases, pathogenesis and progression has been associated with the sustained presence of trafficking cells, with examples including chronic diseases such as Chronic Obstructive Pulmonary Disease and Idiopathic Pulmonary Fibrosis and acute infections such as Pneumonia and Pneumonitis. In these instances, there is evidence that dysfunctional and sustained recruitment of cells to the airways not only increases host damage but impairs the hosts ability to effectively respond to microbial invasion. Targeting leukocyte migration in these instances, to normalise cellular responses, has therapeutic promise. In this review we discuss the current evidence to support the trafficking cell as an immunotherapeutic target in lung disease, and which potential mechanisms or pathways have shown promise in early drug trials, with a focus on the neutrophil, as the quintessential trafficking immune cell.

Keywords: neutrophil (PMN), respiratory, ageing, proteinase, chemotaxis, monocyte 


\section{INTRODUCTION}

The lungs, especially the alveolar network, are the area of the body where the external environment is in closest proximity to the circulating blood. The average diameter of the alveolar membrane is $0.2 \mu \mathrm{m}$, and each minute, approximately $5 \mathrm{~L}$ of blood and 5-8L of air (and the pollutants and microbes contained therein) pass through these organs, which have an internal surface area of 50-75 square metres. The lungs serve to enable gaseous exchange, but also need to preserve health by preventing damage caused by infections or inflammation. In health, the lungs maintain homeostasis through complex interactions between the lung microbiome (defined recently as the characteristic microbial community occupying the lungs, prone to change in time and scale and thought crucial for host function and health) (1), resident immune cells and defences and the trafficking of non-resident immune cells from the systemic circulation to the lung in the presence of more challenging inflammation, infection or injury.

Non-resident immune cells include neutrophils, eosinophils and monocytes, all of which are involved in the inflammatory process. The exact make up of both the trafficking cell type and cellular phenotype within cell types depends on the nature of the challenge, but an optimal response includes a swift and accurate recruitment of cells to the location of the injury or infection, clearance of the threat (be that pathogens or inflamed/necrotic tissue) through phagocytosis, and then resolution of inflammation via programmed cell death and clearance by efferocytosis or expectoration (within sputum) or retrograde migration back into the circulation (2). Phagocytosis of pathogens should lead to pathogen-killing through exposure to proteinases (especially in the case of neutrophils), bactericidal proteins or reactive oxygen species, combined and contained within phagolysosomes. This intracellular process limits host tissue exposure to injurious enzymes, but extracellular release does occur (as part of degranulation, so called 'sloppy eating' or during NETosis) and here, local tissue damage is unavoidable, although limited by the presence of anti-oxidants and antiproteinases (3).

Pro and anti-inflammatory signals leading to immune cell recruitment and immune cell clearance are held in exquisite balance by cross talk between resident tissue and the migratory cells as the inflammatory challenge is overcome. When these processes go awry, through excessive, sustained cell recruitment, inaccurate migration, or impaired clearance; unresolved inflammation can lead to lung damage and contribute to the development of chronic lung disease. This can lead to a vicious cycle of lung damage, described first in Cole's theory of bronchiectasis [a suppurative lung disease (4)], where tissue damage leads to an increased susceptibility to infection, which leads to immune cell recruitment and degranulation, with proteinases capable of digesting all components of the extracellular matrix, which leads to increased inflammation and subsequent on-going tissue damage. There is significant interest in therapeutically breaking this cycle, potentially limiting subsequent lung damage and maintaining lung health.
Initially it was assumed that excessive immune cell recruitment to the lung was a normal, physiological response to a pathological stimulus. In this model, only the recruiting stimuli (the lung inflammation or the microbe) could be targeted to reduce cell infiltration. It was thought that targeting the trafficking immune cell would lead to immunoparesis and impair the ability to respond to subsequent infections, placing the host at risk. However, there is increasing evidence of altered and dysfunctional migrating cell behaviour in chronic and acute lung disease $(5,6)$, and emerging evidence that targeting leukocyte trafficking may improve these cells responses to infection while reducing absolute numbers of cells in the lungs, thus reducing the inflammatory burden. See Figure 1 for an overview of this.

This review will discuss the current evidence to support the trafficking cell as an immunotherapeutic target in lung disease, and which potential mechanisms or pathways have shown promise in early drug trials, with a focus on the neutrophil, as the quintessential trafficking immune cell.

\section{LEUKOCYTE TRAFFICKING FROM THE BLOOD}

\section{Pro-Migratory Signals}

Inflammation within the lung parenchyma leads to the release of a milieu of cytokines and chemokines from damaged epithelial cells, as well as activated alveolar macrophages and other resident or recruited immune cells such as neutrophils and $\mathrm{T}$ cells. Chemokines attract leukocytes with varying affinity and capacity. They are divided into groups based on the position of their conserved cysteine residues, with the CXC and CC families the most important for inflammatory disease (7). CXCL-8 and CXCL2 are important neutrophil chemokines, acting via tCXCR-1 and CXCR-2 receptors (8), alongside monocyte chemoattractant protein (MCP-1) for monocytes, which acts on the CCL2 receptor, resulting in monocyte recruitment and macrophage activation (9). These topics have been extensively reviewed elsewhere (10).

Initially it was thought that there was a simple relationship between the release of Damage-associated molecular patterns (DAMPs) and leukocyte recruitment. However, the complexity of signalling cascades from inflamed tissues is increasingly recognised. As vital components of the host defence, leukocytes must sense, prioritize and integrate all of the chemotactic cues from the environment into a migration response towards damaged tissues (11). To achieve this, neutrophils express more than 30 different receptors able to sense pro-inflammatory mediators and modulate neutrophil migration (12), whereas monocytes express various receptors depending on their subset (13).

The migration of neutrophils to inflamed tissues is thought to occur in phases. Early neutrophil recruitment ("scouting" cells) respond to tissue DAMPs through the SRC family kinase LYN. DAMPs induce the production of CXC-chemokines and 


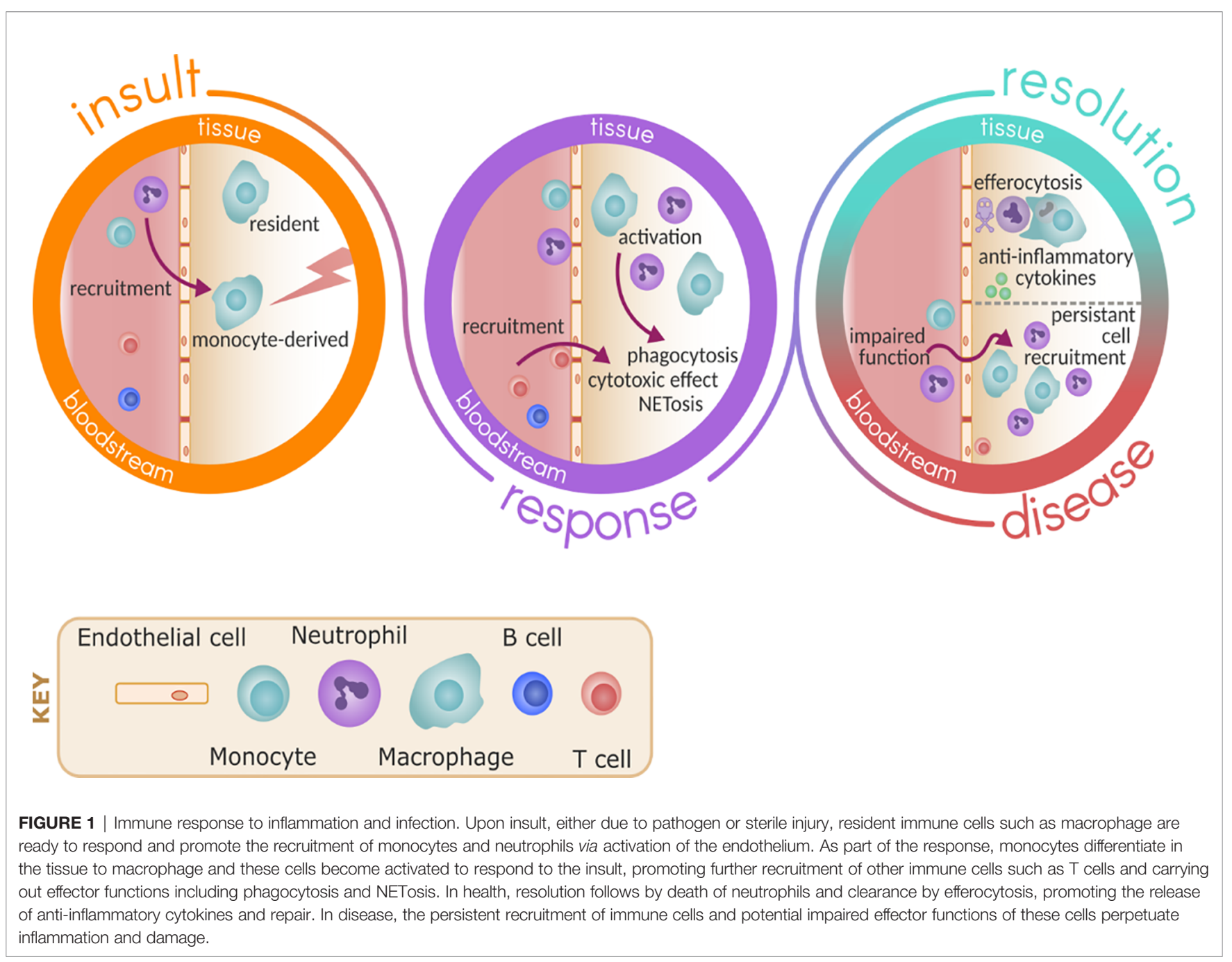

leukotrienes from surrounding tissues (14). Early-arriving neutrophils add to this inflammatory cocktail, as, through activation, neutrophils directly and indirectly promote further secretion of CXCL8 and leukotriene B4 (LTB4) to induce further neutrophil recruitment from the circulation. The fine control of neutrophil extravasation is seen with CXCL1 promoting crawling of neutrophils along blood endothelial cells and then CXCL2 promoting unidirectional movement across the endothelium (15). In infection, the release of pathogenassociated molecular patterns (PAMPs) and the presence of other recruited immune cells prolongs and amplifies neutrophil infiltration. There appears to be a signal hierarchy with DAMPS and cytokines such as CXCL8 forming a migratory "start" signal which can be superseded or ignored in the presence of PAMPs such as fMLP $(16,17)$.

Monocytes exert many of their functions outside the vascular compartment, thus requiring trafficking to tissues. Monocytes in the tissues respond to chemokines and cytokines, differentiating into macrophages or dendritic cells during infection, as well as wound-associated macrophages or tumour induced myeloid suppressor cells (18). However, monocytes can also remain undifferentiated, at least in the resting state.

\section{The Components of Leukocyte Trafficking From the Systemic Circulation}

In health, neutrophils and monocytes are released from the bone marrow in a quiescent state and maintain this in the circulation during homeostasis. They become primed in response to an initial activation signal via a plethora of agents, including bacterial products, cytokines and metabolic cues (19) and can then become activated whereby effector responses are deployed (20). Originally, the focus on neutrophil priming was on enhancing the ROS response (19), but is now known to also control other aspects of cell function including adhesion (21) and chemotaxis (22). Primed neutrophils also show a slower transit time through the lung vasculature, shown in patients that have inflammatory lung diseases such as COPD (23) or even lowgrade inflammation (24). Priming of other immune cells such as macrophage has also been described, whereby metabolic signals such as exogenous heme or apoptotic bodies induce changes 
allowing the macrophage to respond to a later pathogenic and activating signal (25).

Leukocytes are recruited to the lung from the pulmonary and bronchial circulation, including alveolar capillaries and postcapillary venules. Recruitment of leukocytes to the lungs is a complex process, tightly regulated by both leukocytes and the vascular endothelium. In the bronchial circulation, or in larger vessels, the leukocyte trafficking cascade can be broadly split into three stages: rolling, firm adhesion, and extravasation or transmigration (26). Each of these stages has distinct groups of adhesion molecules that govern the interaction of leukocytes with the endothelium (27).

\section{Rolling}

Endothelial cells within the blood vessels detect chemokines and are able to rapidly increase the expression of P-selectin (CD62P) $(28,29)$ and E-selectin (CD62E) $(30)$. These two selectins can be bound by $\mathrm{P}$-selectin glycoprotein ligand-1 (PSGL-1) which, despite its name, can bind all three main selectins (CD62P, E and L) (31). PSGL-1 is expressed on the surface of neutrophils and monocytes $(32,33)$ allowing for increased interaction between activated endothelium and passing leukocytes (31). CD62L is the only selectin expressed by neutrophils (34), but also by monocytes (35) and is maintained on the plasma membrane (36). Human neutrophils are also able to directly bind CD62E with CD62L (37). PSGL-1 is also expressed by activated endothelium (38) and is, therefore, capable of also binding to CD62L on the surface of the leukocyte. Together, the expression of selectins and PSGL-1 results in rolling - a process that occurs under shear stress in the circulation, and indeed requires shear stress to function correctly (39). These interactions provide multiple points for pharmacological intervention to either block or enhance leukocyte recruitment to sites of activated endothelium.

\section{Extravasation/Transmigration}

At the point of firm adhesion and rolling arrest, two processes can occur: crawling along the vascular lumen or transmigration into the tissue. Intraluminal crawling has been visualised in vivo in mice using intravital microscopy, identifying the reliance on LFA-1 for initial adhesion and Mac-1 for efficient crawling (40). Transmigration predominantly occurs paracellularly (between endothelial cell junctions) (41), however, movement through the endothelial cytoplasm, known as transcellular migration (42), has also been described in vitro (43).

Two major signalling pathways have been identified as of central importance neutrophil chemotaxis: PI3K and MAPK (16). Responses to intermediate chemoattractants are heavily reliant on the dual action of phosphoinositide 3-kinase (PI3K), specifically the gamma and delta isoforms in human leukocytes, at the leading edge and phosphatase and tensin homolog (PTEN) at the lagging edge $(44,45)$ - two enzymes that control the phosphorylation of phosphatidylinositol. In contrast, p38 MAPK co-ordinates neutrophil chemotaxis to end-point chemoattractants (46).

The process of cellular recruitment through the pulmonary vasculature is thought to occur via slightly different processes, dependant on adhesion receptor expression (42). At their smallest diameter, tight and tortuous pulmonary capillaries have an internal diameter of less than $2 \mu \mathrm{m}$, significantly smaller than a neutrophil, which, in an unpolarised form, has a diameter of approximately $7 \mu \mathrm{m}$. Despite this, in vivo studies have demonstrated that in health, human neutrophils are able to pass through the pulmonary capillaries with a similar speed to red blood cells (47). Furthermore, the deformation of the neutrophil in passing through these capillaries may actually provide an innate mechanical mechanism to 'de-prime' neutrophils in the circulation: neutrophils that were artificially primed ex-vivo and reintroduced to the host circulation initially increased their transit time through the lungs, but this effect was slowly lost (47). Complementing these findings, forced mechanical deformation ex-vivo of neutrophils also reversed the changes observed in primed neutrophils, suggesting a mechanism of depriming (48). Neutrophil transit though narrow capillaries, such as those in the pulmonary vasculature, might, therefore, have important functions for immunomodulation, allowing primed neutrophils to return to the quiescent state.

\section{Response Within the Parenchyma}

Neutrophils are the first wave of leukocytes to arrive in the lungs upon infection, followed by monocytes $(10,49)$. To migrate through the dense and elastic extracellular matrix of the lungs, it has been suggested that neutrophils release small amounts of proteinases and then reactive oxygen species sequentially (50). Inflamed tissue tends to be hypoxic and lactataemic, conditions that promote neutrophil survival via a distinct signalling pathway involving hypoxia-inducible factor $1 \alpha$ (HIF-1) (51). In the lungs, neutrophils actively kill invading pathogens by a number of processes, including phagocytosis and by the release of antimicrobial molecules including reactive oxygen species (ROS) and neutrophil extracellular traps (NETs) (52). Once in the lungs and in response to inflammatory stimuli, monocytes differentiate into monocyte-derived macrophages (MDM) or monocyte-derived dendritic cells (MoDC) dependant on the microenvironment (53).

On resolution of inflammation, a proportion of neutrophils die by apoptosis, and many are cleared by macrophages through a process called efferocytosis (54). Apoptosis is triggered either by intrinsic loss of mitochondrial membrane integrity, causing release of cytochrome $\mathrm{c}$ into the cytoplasm and promoting activation of caspase 3; or by extrinsic signalling through death receptors to drive caspase 8-dependant activation of caspase 3 (55). Apoptosis triggers the externalisation of phosphatidylserine (PS), an 'eat me' signal, as well as downregulation of 'don't eat me' signals CD47 and CD31. This process can be regulated by the cell, suggesting modulation of the pathways and receptors involved may be a mechanism by which efferocytosis of excessively trafficked neutrophils could be enhanced in lung disease (54).

Other mechanisms of clearance of neutrophils and other dying immune cells from the lung include via the mucociliary escalator (56), whereby ciliated epithelial cells covered with a mucus layer beat synchronously to move entrapped particulates, including cells, up to the throat for removal by expectoration. In lung diseases such as COPD and IPF, there are both increases in 
mucus production and expectoration and increases in the number of trafficking cells within these secretions $(57,58)$. Neutrophils may also leave the site of inflammation through a process known as reverse transmigration, whereby neutrophils migrate across the endothelium and re-enter the vasculature (59). Although not yet fully characterised this, and integrins which are needed for this activity, may be another therapeutic target.

Neutrophil phagocytosis occurs through direct interactions between bacteria and immune cells ("unopsonised phagocytosis") but is more efficient when bacteria are coated with immunoglobulins and complement ("opsonised phagocytosis"). Optimal opsonisation requires both immunoglobulins and complement (60). However, unopposed neutrophil elastase can impede both immunoglobulin and complement activity, cleaving the hinge region of $\operatorname{IgA}$ and complement $\mathrm{C} 3 \mathrm{bi}$, forming a functional opsonin mismatch $(61,62)$ which may be important in predisposing the host to secondary lung infections in chronic illness.

Neutrophils are not the only cells implicated in these processes. Monocytes are able to phagocytosis to a small extent, but they are also key modulators of the immune response through inflammatory mediator release. In response to inflammatory stimuli, monocytes are induced to differentiate into MDM through high levels of GMCSF in the lungs, which is elevated during inflammation (63). MDM add to the pool of local alveolar macrophages, and contribute to high levels of phagocytosis of bacteria, inflammatory mediator release and, on resolution of inflammation, efferocytosis of dying neutrophils and epithelial cells, to ensure safe clearance of these dying cells $(10,54)$. MoDC also supplement the local pool of dendritic cells, to take up infectious agents, process and present antigen on the cell surface, followed by migration to the lymph nodes to activate $\mathrm{T}$ cells and the adaptive immune response (64).

The containment of the inflammatory signal to where it is needed, for only as long as needed is especially important in lung tissue. The lungs rely on their elastic properties to maintain adequate ventilation. Elastic fibres are highly complex matrix structures because of their size, molecular complexity, and the requirement for numerous helper proteins to facilitate fibre assembly (65). Previous studies have conclusively shown that elastin degradation caused by neutrophil proteinases is a key step in the pathogenesis of many chronic lung diseases and that lung cells are unable to repair damaged elastic fibres, leading to permanently compromised lung function and ongoing degenerative disease (66).

\section{CHANGES WITH AGE AND IN LUNG DISEASE}

Alterations in the innate immune response have been identified in lung diseases including COPD and IPF, but it is important to note that most lung diseases are more common with advancing age, and there are changes to both the structure and function of the lung and immune cells (including neutrophil) responses with age, which might influence cellular trafficking. This has identified a number of processes that could be targeted for treatment.

\section{Ageing}

Increased age is associated with both elevated rates of infections and chronic lung disease, as well as worse outcomes after illness or injury. In the UK, 95\% deaths from pneumonia (67) and $86 \%$ of deaths from influenzae (68) were in those over 65 years of age. During the COVID-19 pandemic, 73\% of deaths recorded so far occurred in those aged 75 or over (69). Over $90 \%$ of those with COPD (70), $75 \%$ of those with IPF (71) and $90 \%$ of those with bronchiectasis (67) are aged over 65 years of age. This elevated risk is likely due to a number of factors. There are age-associated changes to the lung structure and function. These include a less compliant thoracic cage; a weaker diaphragm; less elastic lung parenchyma leading to senile emphysema; reduced efficiency of the muco-ciliary escalator reducing the clearance of bacteria and microparticles from the lung as well as a reduced ability to maintain homeostasis (including reduced responsiveness to hypoxia and hypercapnia) (72). Ageing is associated with chronic low grade inflammation characterised by increased basal levels of cytokines including Interleukin (IL)-1, IL-6 and tumour necrosis factor (TNF)- $\alpha$ (73). The function of the immune system can also alter with age, termed immunosenesence, with impaired innate and adaptive immune responses to infections and inflammation, and this includes alterations in most neutrophil cellular functions.

Neutrophils show a gradual decline in the accuracy of migration (chemotaxis) with increasing age, although chemokinesis, or the ability to move in any direction, appears unaltered $(74,75)$. Imprecise migration is thought to have significant consequences, leading to both a delay in reaching the site of inflammation, but also contributing to inflammation, as these cells appear to release both proteinases and reactive oxygen species during their convoluted migratory pathways. The deficit is associated with frailty, with adults displaying more pronounced frailty having the most impaired neutrophil responses (76). In vitro studies have suggested impaired migration can be restored to levels which reflect those of a younger adult by inhibiting PI3K, especially gamma and delta isoforms, indicating involvement of this pathway $(77,78)$. As well as alteration to migration, neutrophils that are recruited to the aged lungs show suboptimal superoxide generation and degranulation, and reduced phagocytosis $(79,80)$. The cause of these changes is unclear, but in vitro work suggests that merely exposing neutrophils to the inflammation found with age (by incubating cells from young adults with plasma or serum from older adults) is insufficient to reproduce the cellular phenotype, suggesting the altered functions are not merely a consequence of the inflammatory environment $(76,77)$.

Once again, these age-related changes are not only seen in neutrophils. Monocytes also show changes during ageing, with levels of intermediate (CD14++CD16+) and non-classical $(\mathrm{CD} 14+\mathrm{CD} 16++)$ monocytes increased compared to younger adults. These cells also show impaired phagocytosis, altered cytokine release and elevated expression of migration marker CD11b (81, 82). On stimulation, aged monocytes produce less inflammatory cytokines including IL-1 $\beta$, TNF $\alpha$, IL- 6 and IFN $\alpha$ (83-85) which may contribute to susceptibility to respiratory infection. As with neutrophils, there is a link with frailty and increased monocyte number, however it is as of yet unclear how 
this relates to cell function (86). Mitochondria in aged classical monocytes have reduced membrane potential compared to young monocytes, which may impair cell function due to impaired energy generation (87). Further analysis of metabolic effects of aging on monocyte function may reveal novel insights about the role of these cells in normal aging.

\section{Neutrophil Trafficking in Lung Disease}

There is evidence that the detrimental changes to cellular function seen with age are heightened in lung disease and indeed most chronic and acute lung diseases are associated with an influx of neutrophils to the airways as well as neutrophilic inflammation. Hypoxia is another feature of lung disease, with the potential to alter neutrophil responses further, as described above. Indeed, across many lung diseases, pathogenesis and progression has been associated with an exaggerated and sustained presence of trafficking cells, with specific examples discussed below.

\section{Chronic Obstructive Pulmonary Disease}

$\mathrm{COPD}$ is a common, debilitating and chronic disease thought to affect $10 \%$ of the adult population. It is currently the fourth leading cause of death globally and defined by persistent respiratory symptoms and airflow limitation which is associated with airways inflammation (88). The disease is often complicated by acute worsening of symptoms, termed exacerbations and commonly caused by viral or bacterial infections (89). Innate immune cells are considered to be key drivers of COPD. COPD is associated with greatly increased numbers of neutrophils in lung secretions, having been recruited from the systemic circulation into the airways due to epithelial damage, inflammation and infection (2). Both the lung tissue and secretions contain elevated numbers of macrophages $(20 \mathrm{x})$ as a result of elevated influx of monocytes which differentiate into monocyte derived macrophages (90-92).

Alveolar macrophages are likely to be a key driver of elevated leukocyte recruitment to the lungs during COPD, with COPD sputum and bronchi-alveolar lavage (BAL) containing elevated levels of CXCL-8 (93), LTB4, growth-related oncogene (GRO) alpha $(94,95)$, and MCP-1 (96), amongst other inflammatory agents.

Despite this high number of neutrophils and macrophages in the lungs or airways of patients with COPD, patients suffer with recurrent infections which suggests these cells are dysfunctional (53). In keeping with this, neutrophils from patients with COPD from mild to severe disease have been shown to have an increased speed of migration but also a reduced accuracy of migration towards single chemokines, bacterial products and sputum, associated with reduced pseudopod extension but correctable with PI3K inhibition (97). Of note, similar characteristics were seen in smokers aged between 30 and 40 years of age with respiratory symptoms including chronic bronchitis but no airflow obstruction (98), suggesting altered cellular functions are an early manifestation of disease. Once established the airways inflammation and altered cellular functions appear to persist even after smoking cessation, with heighted cell trafficking to the lungs seen even many years after the patients have stopped smoking (99).
Monocytes from COPD patients show enhanced migration to chemoattractant, which may contribute to enhanced levels of MDM in the COPD lung (100). These monocytes display a heightened pro-inflammatory phenotype, including elevated IL-6 and MCP-1 release (101), but do not show impaired phagocytosis compared to AMC (102). Monocyte-derived macrophage phagocytosis is impaired in COPD $(102,103)$, alongside impaired mitochondrial function (104) which implicates defective monocytes as pre-cursers to these cells.

\section{Idiopathic Pulmonary Fibrosis}

Idiopathic pulmonary fibrosis (IPF) is a progressive condition believed to arise in genetically susceptible individuals as a consequence of an aberrant wound-healing response following repetitive alveolar injury. It is characterised by progressive deposition of extracellular matrix and collagen within the interstitium of the lung, leading to impaired gas exchange, breathlessness and eventually death. The involvement of leukocytes is acknowledged but remains unclear. CXCL-8 levels are elevated in IPF, with BAL neutrophilia a risk factor for early death. Neutrophil elastase damages epithelial cells, and it has been hypothesised that this damage and the subsequent release of DAMPS drives ECM component turnover. Indeed, NE deficient mice are resistant to bleomycin induced PF, however the role in humans is still unclear (105) just as it is unclear what drives the neutrophil recruitment to the lungs in the first instance.

Recently, a role for $\mathrm{N}$-formyl peptide (fMLF) receptors (FPRs) has been described, which might be specific for lung fibrosis. FPR-1-deficient (fpr1-/-) mice are protected from bleomycin-induced pulmonary fibrosis but can develop renal and hepatic fibrosis as normal with the model utilised (106). It is known that infections can drive IPF progression, so potentially the neutrophils may have initially been recruited in response to an infective event, with subsequent recruitment reflecting the abnormal response to wound repair (107). However, the initiating driver of recruitment might reflect other stimuli, as an increasing number of alternative, non-formyl peptide ligands for FPR-1 are being uncovered. Monocytes and macrophages may play a role in disease pathogenesis, although this is yet to be fully determined. Depletion of murine LyC6 monocytes reduces both alveolar macrophages and fibrosis in mice (108), while in humans, an association has been described between monocyte numbers and survival in IPF, with a high monocyte count linked to poorer outcomes (109).

\section{Community Acquired Pneumonia}

It is not just chronic disease where altered leukocyte functions, including neutrophil migration, are associated with poor outcomes. During Community Acquired Pneumonia (CAP), neutrophils are recruited to the airways in high numbers, with the alveolar spaces becoming filled with an exudate made up of inflammatory cytokines, immune cells and systemic proteins leading to hypoxia and ventilation/perfusion mismatch. Neutrophil functions have been shown to be impaired in CAP, with reduced migratory accuracy but increased degranulation and NETosis (110). Of note, in older adults, the defect appears 
sustained and to worsen with the severity of the infectious event, with less dysfunction in simple lower respiratory tract infections and most dysfunction when CAP is associated with sepsis (111). In this instance, dysfunction could be replicated by exposure to plasma from septic patients (110), suggesting the inflammatory systemic environment adds to the cellular dysfunction. This CAP neutrophil phenotype again appears correctable, with correction associated with improved patient outcomes (112), highlighting the potential benefit of targeting these cells.

\section{CURRENT STRATEGIES TO TARGET LEUKOCYTE TRAFFICKING IN LUNG DISEASES}

The wealth of evidence describing the negative associations with lung disease and excessive or sustained leukocyte influx into the lungs highlights the need to target these processes, without compromising the hosts' ability to respond to infections. A plethora of drugs targeting leukocyte trafficking have been developed, however, many to date have failed to make it to market for respiratory diseases. Table 1 describes the potential targets and therapies developed, but key examples are provided below and Figure 2 provides an overview of potential mechanisms.

\section{Targeting Priming Agents, Chemokines or Their Receptors CXCR2 Inhibitors}

CXCR2 is a major neutrophil and monocyte chemokine receptor, responsible for controlling migration towards ligands such as CXCL8. Inhibition of CXCR2 signalling is, therefore, an attractive target to dampen recruitment to CXCL8-rich tissue. The first report of a selective CXCR2 antagonist demonstrated reduced neutrophil migration to CXCL8 both in vitro using human neutrophils and in vivo blockade of neutrophil margination within rabbits (120). Several studies confirmed that blockade of CXCR2 reduced neutrophilic inflammation including in cigarette smoke-exposed rats (121); in an acute lung injury model in mice (122) and in an LPS airway challenge model in guinea pigs (123). Despite broad evidence from in vivo and in vitro models, clinical trials using CXCR2 antagonists provided a mixed picture.

The CXCR2 antagonist MK-7123 was used at various doses in a small phase 2 study including 616 patients with COPD, reporting that the highest dose of MK-7123 was able to improve $\mathrm{FEV}_{1}$ and increase the time to exacerbation, indicating a clinical benefit to patients. However, reductions in absolute neutrophil counts led to withdrawal of $18 \%$ of patients for safety reasons and there was also a significant increase in the inflammatory marker, C-Reactive protein (CRP) (124).

In a clinical trial of danirixin, another CXCR2 inhibitor, initial studies suggested clinical benefit in COPD (116). A subsequent larger trial (including 614 COPD patients) (116) found no significant clinical benefit in respiratory symptoms but significantly exacerbations and pneumonia events in the highest dose group, suggesting impairments in host responses to infection.

\section{Targeting Other Chemokines and Their Receptors}

$\mathrm{LTB}_{4}$ is a potent and proinflammatory chemoattractant, synthesised by neutrophils following the enzymatic conversion of arachidonic acid and facilitated by 5-lipoxygenase activating protein (FLAP). A study by Crooks et al. showed an increased concentration of $\mathrm{LTB}_{4}$ at presentation of infective exacerbation, compared to resolution of exacerbation, in a cohort of chronic bronchitis patients. Moreover, this finding coincided with an increase in sputum chemotactic and MPO activity, suggesting the role of $\mathrm{LTB}_{4}$ in bronchial inflammation (125).

Blockade of $\mathrm{LTB}_{4}$ was investigated in a phase II, randomised and placebo-controlled trial in a small cohort $(n=17)$ of stable COPD patients (115). Participants were randomised to receive BAYx1005, an antagonist against FLAP, or placebo, for 14 days. Follow-up spontaneous sputum collection (day 14) revealed significant reduction of $\mathrm{LTB}_{4}$, compared to baseline, in the treated group. Although this reduction did not show complete suppression of $\mathrm{LTB}_{4}$, the observed change was similar to that observed at resolution of an exacerbation of chronic bronchitis. Hence, this trial suggested

TABLE 1 | Therapeutic agents that target leukocyte function and their clinical trial results.

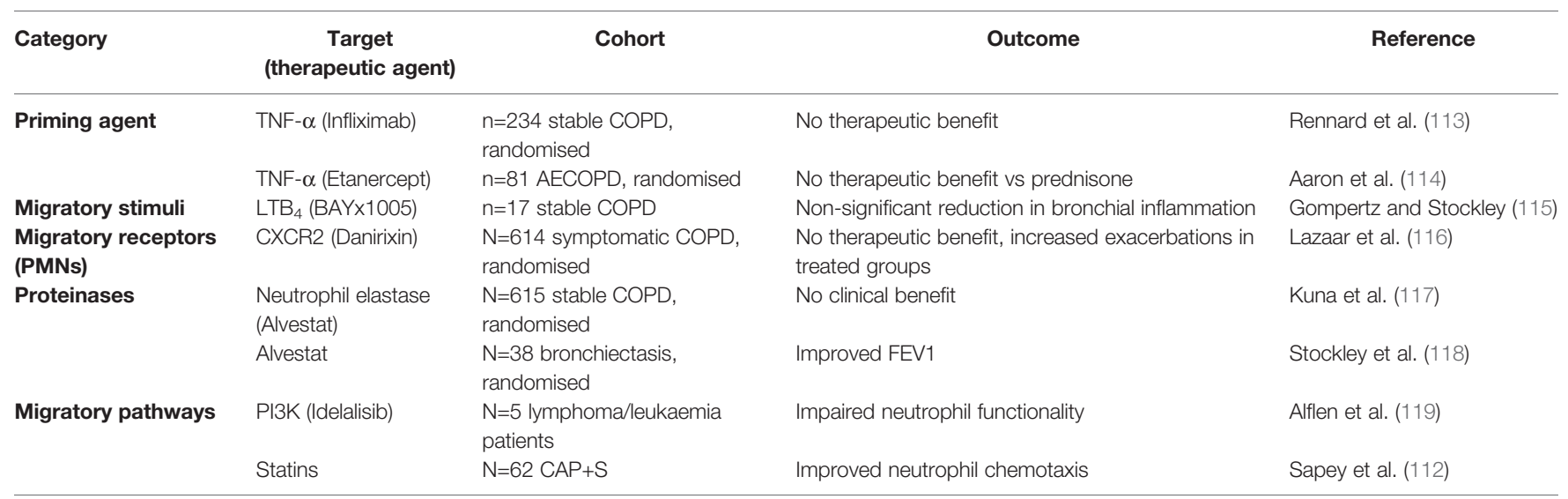

A non-exhaustive list of the targets identified for leukocyte trafficking in lung disease, and the initial results of clinical studies. 


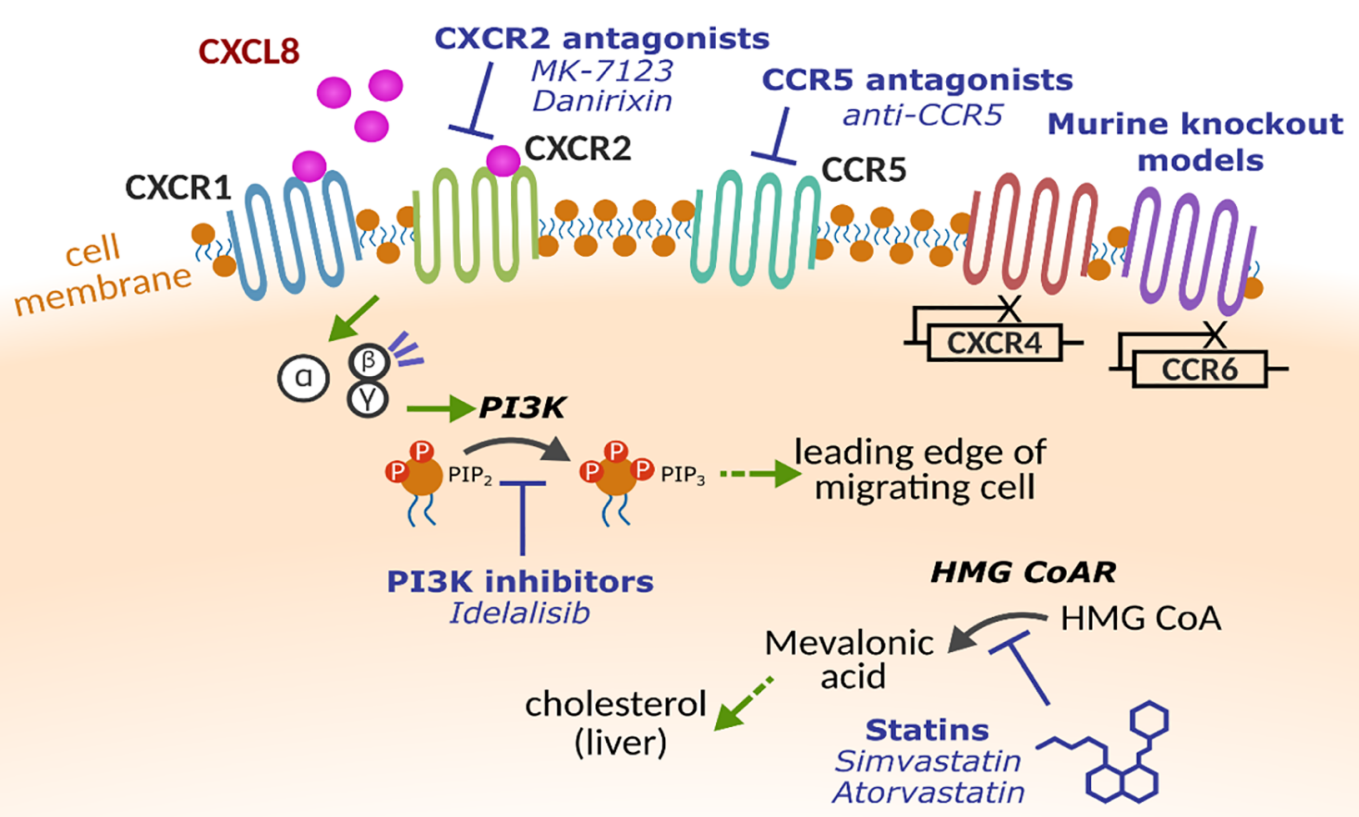

FIGURE 2 | Molecular targets for altering leukocyte trafficking. Multiple receptors and proteins have been targeted to alter leukocyte trafficking. Chemokine receptors CXCR1, CXCR2, CXCR4 CCR5 and CCR6 have all been investigated either using pharmacological intervention or in early studies with gene knockout models. Within the cell, key enzymes such as phosphoinositide 3-kinase (PI3K) and $\beta$-Hydroxy $\beta$-methylglutaryl-CoA reductase (HMG CoAR) that have been implicated in cell motility.

the efficacy of $\mathrm{LTB}_{4}$-blockade for the reduction of neutrophilassociated bronchial inflammation in patients with chronic lung disease.

Animal models of COPD have begun testing other chemokine receptor antagonists to identify promising candidates. CCR6 and CXCR3 knockout mice displayed reduced lung inflammation and evidence of protection against emphysema, when exposed to cigarette smoke $(126,127)$. Treatment with anti-CCR5 in an emphysema mouse model resulted in the reduction of apoptosis, DNA injury and alveolar remodelling with a subsequent reduction in lung inflammation (128). Whether there are any benefits of targeting these receptors in human disease remains to be tested.

\section{Priming Agents}

TNF- $\alpha$ is a priming agent for neutrophils, inducing their expression of $\beta_{2}$ integrins and augmenting cell migration (129). TNF- $\alpha$-induced degranulation, release of reactive oxygen intermediates and phagocytosis gives rise to local and systemic inflammatory responses (130). Given its proinflammatory consequences, studies suggest its role as a primary mediator of inflammation in COPD disease pathogenesis (131). Inhibition of TNF- $\alpha$ in COPD was investigated by Rennard and colleagues who conducted a randomised, placebo-controlled trial to assess the efficacy of TNF- $\alpha$ antagonism in moderate to severe COPD patients (113). A total of 157 patients were randomised to receive
Infliximab, an anti-TNF- $\alpha$ antibody. No benefit was observed in the treated groups compared to placebo, in terms of changes in health status, lung function or exacerbation frequency. A later trial, using an alternative TNF- $\alpha$-antagonist, sought to determine the efficacy of anti-TNF- $\alpha$ for the reduction of inflammation in a cohort of exacerbating COPD patients (114) with no clinical benefits.

\section{Targeting Intracellular Processes PI3K}

The PI3K pathway, activated by binding of ligands to G-protein coupled receptors, or tyrosine kinase receptors on the cell surface, is implicated in numerous leukocyte functions (132). Downstream effectors of PI3K activation include protein kinases that regulate cell motility and membrane trafficking, scaffolding proteins and other signalling processes (133). Neutrophils, monocytes, macrophages and $\mathrm{T}$ cells have all been show to require $\mathrm{PI} 3 \mathrm{~K}$ for chemotaxis, but also for phagocytosis through similar mechanisms of actin remodelling (134). In vitro experiments from neutrophils from older adults and COPD patients showed a relationship between inaccurate neutrophil migration and increased PI3K signalling, and that inhibition of PI3K $\gamma$ or $\delta$ restored accuracy (77). Further in vitro experiments using idelalisib, a PI3K inhibitor used for non-Hodgkin lymphoma, showed that after TREM-1 ligation, idelalisib reduced L-selectin shedding, oxidative burst, degranulation and 
cytokine release in neutrophils (119). The reduction in all key neutrophil functions has led to some concerns about the potential safety of this therapy, with both the potential to normalise and neutralise neutrophil responses. In recognition of this, studies in COPD have used inhaled PI3K inhibitor therapies in the first instance, limiting systemic exposure. First reports suggest signals of clinical benefit (135), but wider trials are needed across all chronic lung diseases.

\section{Repurposing Statins}

Statins, or 3-hydroxy-3-methyl-glutaryl-coenzyme A (HMG CoA) Reductase Inhibitors are primarily used to treat dyslipidaemia. However, their association with reductions in all-cause mortality has led to further exploration of their anti-inflammatory and immunomodulatory properties. Several randomised controlled trials have demonstrated the reduction of systemic inflammation in cohorts treated with statins; a reduction in inflammatory biomarkers, namely high-sensitivity CRP (hsCRP) and IL-6, were observed in those treated with atorvastatin (136). Similarly, a downregulation of IL-8 and immune cell activation was seen in HIV patients treated with pitavastatin (137). Observational studies suggested that statins were associated with a reduction in mortality from pneumonia and influenza, despite patients taking these therapies being older and having more co-morbidities (138). Clinical trials have explored this further (139) and older patients with community acquired pneumonia and sepsis receiving $80 \mathrm{mg}$ simvastatin demonstrated improved neutrophil chemotaxis and reduced systemic neutrophil proteinase burden, as well as improving hospitalisation-free survival compared to placebo (140). Unfortunately, this benefit was not replicated in trials of statins in Acute Respiratory Distress Syndrome (ARDS) (for example (141),) leading to statins falling out of favour as an adjunct treatment. However, when patients were sub-stratified into those with the highest burden of inflammation, those with the most inflammation gained most benefit from a statin intervention (142), suggesting the need for careful patient selection.

In COPD the burden of inflammation rarely meets that seen in pneumonia or ARDS, however it was recently shown that neutrophils isolated from COPD patients, when incubated with simvastatin, improved their migratory dynamics towards CXCL8 and fMLP, to levels similar to aged matched healthy controls (143), indicating a potential benefit of statins directly on leukocyte migration. Meta-analyses have suggested that statins reduce not only cardiovascular risk in COPD, but also acute exacerbations and CRP (144) although this finding has not been universally (145), suggesting further studies are needed.

\section{Targeting Neutrophil Proteinases}

Neutrophil proteinases represent a promising target in chronic respiratory diseases, including COPD, AATD and IPF, as proteinases have been shown to be important in trafficking processes. There are a number of neutrophil elastase inhibitors under development (146).

In AATD, the clear association between neutrophil proteinases and lung disease has led to the use of augmentation therapy of infused AAT. This therapy is already licensed for use in some countries within Europe and the USA, but only for limited indications in the UK. Studies such as the RAPID trial (167 patients, placebo controlled) have demonstrated a reduction in the decline of lung function (147) and smaller studies have highlighted the positive impact of augmentation on neutrophilic inflammation (148). However, not all patients respond, and there is now interest in determining who gains the most benefit, for example by identifying and focusing on those with the fastest decline in lung function (149).

Alvestat (AZD9668) is a selective NE inhibitor with oral availability. In randomised control trials of COPD patients, 12 weeks of treatment with AZD9668 showed no positive effect on exacerbation frequency, symptoms, lung function or inflammatory biomarkers, but with 300 participants on active treatment, the study was likely underpowered for these heterogeneous outcome measures (117). Alvestat has also been studied in bronchiectasis, where 4 weeks of treatment improved $\mathrm{FEV}_{1}$, highlighting a potential signal of benefit (118). More recently, a trial of Brensocatib (an oral reversible inhibitor of dipeptidyl peptidase 1 (DPP-1), an enzyme responsible for the activation of neutrophil serine proteases) showed a reduction sputum neutrophil proteinases and improvements in clinical outcomes in bronchiectasis (150). This has renewed interest in anti-proteinase therapies, with many more trials in development or actively recruiting.

\section{THE CHALLENGES OF TREATMENT EFFICACY}

Despite a strong rationale for targeting recruited immune cells, results of many trials have been negative. This might reflect the heterogeneity of the disease or population under study, a lack of stratification of the patient population, the wrong dose, modality or timing of the intervention.

Inflammation is very heterogeneous both within individuals and between individuals (95) and some studies may be underpowered to see changes in the biomarker they are assessing. Disease heterogeneity is also considerable. For example, COPD is an umbrella term for multiple pathologies and the resulting patient population can be very diverse. Attempting to treat all patients with the same therapy may hide the positive impact the treatment is having on some, due to a lack of effect in others. An example of both of these processes is that studies have highlighted a proportion of COPD patients with a polymorphism in the TNF $\alpha$ receptor, who experience an increased decline in $\mathrm{FEV}_{1}$, low body weight and altered sputum neutrophil recruitment which could be reduced with TNF $\alpha$ antibody (151). Potentially a lack of efficacy of TNF $\alpha$ in COPD trials might reflect a recruited population which has not been enriched for patients with this polymorphism. Other patient characteristics may also influence trial effectiveness. These include smoking status (as smoking retains the pro-inflammatory insult that triggered the disease initially), frequency of exacerbation, and the rate of lung function decline. The biology behind these differences in patient phenotype needs to be understood to allow new targets to be developed or repurposed therapies to be focused.

There have also been inconsistencies in the drug, dose and modality of therapies used in clinical trials. For example, the variable 
results from clinical trials of statins in chronic and acute lung disease might reflect differences in doses (with the greatest effects on cellular function seen at high dose), the population chosen (with most beneficial effects seen in older adults) and the timing of the intervention (with trials focusing earlier in the inflammatory journey having greater impact than those based within the Intensive Care Unit) (152). A more developed understanding will be needed across all these variables before the full impact of immunomodulatory targets can be harnessed for patient benefit.

\section{CONCLUSION}

Leukocyte trafficking represents a promising target for the treatment of acute and chronic respiratory disease. These novel treatments could target the pathophysiology of disease, and so may provide significant impact for patients. However, often the complexity of immune cell trafficking and function and the heterogeneity of both patients and the respiratory disease have been poorly considered, with a "one size fits all" approach deployed in clinical trials.

\section{REFERENCES}

1. Berg G, Rybakova D, Fischer D, Cernava T, Shloter M. Microbiome Definition Re-Visited: Old Concepts and New Challenges. Microbiome (2020) 8(1):119. doi: 10.1186/s40168-020-00905-x

2. Jasper AE, McIver MJ, Sapey E, Walton G. Understanding the Role of Neutrophils in Chronic Inflammatory Airway Disease. F1000 Res (2019) 8. doi: 10.12688/f1000research.18411.1

3. Kaplan MJ, Radic M. Neutrophil Extracellular Traps (Nets): Double-edged Swords of Innate Immunity. J Immunol (2012) 189(6):2689-95. doi: 10.4049/jimmunol.1201719

4. Cole PJ. Inflammation: A Two-Edged Sword-the Model of Bronchiectasis. Eur J Respir Dis (1986) 147:6-15.

5. Galani IE, Andreakos E. Neutrophils in Viral Infections: Current Concepts and Caveats. J Leukoc Biol (2015) 98(4):557-64. doi: 10.1189/jlb.4VMR1114-555R

6. Kumar KP, Nicholls AJ, Wong CHY. Partners in Crime: Neutrophils and Monocytes/Macrophages in Inflammation and Disease. Cell Tissue Res (2018) 371(3):551-65. doi: 10.1007/s00441-017-2753-2

7. Baggiolini M, Dewald B, Moser B. Interleukin-8 and Related Chemotactic Cytokines-CXC and CC Chemokines. Adv Immunol (1994) 55:97-179. doi: 10.1016/S0065-2776(08)60509-X

8. Ludwig A, Peterson F, Zahn S, Gotze O, Schroder JM, Flad HD, et al. The CXC-chemokine Neutrophil-Activating Peptide-2 Induces Two Distinct Optima of Neutrophil Chemotaxis by Differential Interaction With Interleukin-8 Receptors CXCR-1 and CXCR-2. Blood (1997) 90:4588-97. doi: 10.1182/blood.V90.11.4588.4588_4588_4597

9. de Boer WI, Sont JK, van Schadewijk A, Stolk J, van Krieken JH, Hiemstra PS. Monocyte Chemoattractant Protein 1, Interleukin 8, and Chronic Airways Inflammation in COPD. J Pathol (2000) 190:619-26. doi: 10.1002/(SICI)1096-9896(200004)190:5<619::AID-PATH555>3.0.CO;2-6

10. Shi C, Pamer EG. Monocyte Recruitment During Infection and Inflammation. In: Nature Reviews Immunology. NIH Public Access (2011). p. 762-74. doi: 10.1038/nri3070

11. Gambardella L, Vermeren S. Molecular Players in Neutrophil ChemotaxisFocus on PI3K and Small Gtpases. J Leukocyte Biol (2013) 94:603-12. doi: 10.1189/jlb.1112564

12. Futosi K, Fodor S, Mocsai A. Neutrophil Cell Surface Receptors and Their Intracellular Signal Transduction Pathways. Internatinal Immunopharmcol (2013) 17:638-50. doi: 10.1016/j.intimp.2013.06.034

13. Shi C, Pamer EG. Monocyte Recruitment During Infection and Inflammation. Nat Rev Immunol (2011) 11(11):762-74. doi: 10.1038/nri3070
Our increased understanding of physiological and pathological immune cell responses provides an opportunity to rethink clinical trials in this space. Recent studies have shown more promise when targeting trafficking cells, and the learning from these studies have led to the expectation of a raft of new immunomodulatory therapies for lung disease in the near future.

\section{AUTHOR CONTRIBUTIONS}

$\mathrm{KB}, \mathrm{MH}, \mathrm{DS}, \mathrm{EW}$, and ES wrote the first version of the manuscript. ES finalised content. All authors contributed to the article and approved the submitted version.

\section{FUNDING}

$\mathrm{KB}$ is funded by the MRC and Alpha 1 Foundation. $\mathrm{MH}$ is funded by The Wellcome Trust. EW is funded by the Alpha 1 Foundation. ES is funded by MRC, ISCF, EPSRC, ERDF, Alpha 1 Foundation.

14. Rohwedder I, Kurz ARM, Pruenster M, Immler R, Pick R, Eggersmann T, et al. Src Family Kinase-Mediated Vesicle Trafficking Is Critical for Neutrophil Basement Membrane Penetration. Haematologica (2020) 105:1845-56. doi: 10.3324/haematol.2019.225722

15. Girbl T, Lenn T, Perez L, Rolas L, Barkaway A, Thiriot A, et al. Distinct Compartmentalization of the Chemokines CXCL1 and CXCL2 and the Atypical Receptor ACKR1 Determine Discrete Stages of Neutrophil Diapedesis. Immunity (2018) 49:1062-76. doi: 10.1016/j.immuni.2018.09.018

16. Heit B, Tavener S, Raharjo E, Kubes P. An Intracellular Signaling Hierarchy Determines Direction of Migration in Opposing Chemotactic Gradients. J Cell Biol (2002) 159:91-102. doi: 10.1083/jcb.200202114

17. Kim D, Haynes CL. Neutrophil Chemotaxis Within a Competing Gradient of Chemoattractants. Analyt Chem (2012) 84:6070-8. doi: 10.1021/ ac3009548

18. Teh YC, Ding JL, Ng LG, Chong SZ. Capturing the Fantastic Voyage of Monocytes Through Time and Space. Front Immunol (2019) 10:834. doi: 10.3389/fimmu.2019.00834

19. Miralda I, Uriarte SM, McLeish KR. Multiple Phenotypic Changes Define Neutrophil Priming. Front Cell Infect Microbiol (2017) 7:217. doi: 10.3389/ fcimb.2017.00217

20. Sapey E, Stockley RA. Red, Amber and Green: The Role of the Lung in DePriming Active Systemic Neutrophils. Thorax (2014) 69:606-8. doi: 10.1136/ thoraxjnl-2014-205438

21. Condliffe AM, Chilver ER, Haslett C, Dransfield I. Priming Differentially Regulates Neutrophil Adhesion Molecule Expression/Function. Immunology (1996) 89(1):105-11. doi: 10.1046/j.1365-2567.1996.d01-711.x

22. Montecucco F, Steffens S, Burger F, Da Costa A, Bianchi G, Bertolotto M, et al. Tumor Necrosis Factor-Alpha (TNF- $\alpha$ ) Induces Integrin CD11b/ CD18 (Mac-1) Up-Regulation and Migration to the CC Chemokine CCL3 (Mip-1 $\alpha$ ) on Human Neutrophils Through Defined Signalling Pathways. Cell Signal (2008) 20(3):557-68. doi: 10.1016/j.cellsig. 2007.11.008

23. Tregay N, Begg M, Cahn A, Farahi N, Povery K, Madhavan S, et al. Use of Autologous 99mTechnetium-Labelled Neutrophils to Quantify Lung Neutrophil Clearance in COPD. Thorax (2019) 74(7). doi: 10.1136/ thoraxjnl-2018-212509

24. Vogt KL, Summers C, Chilvers ER, Condliffe AM. Priming and De-Priming of Neutrophil Responses In Vitro and In Vivo. Eur J Clin Invest (2018) 48 (52):e12967. doi: 10.1111/eci.12967

25. Glass CK, Natoli G. Molecular Control of Activation and Priming in Macrophages. Nat Immunol (2016) 17(1):26-33. doi: 10.1038/ni.3306 
26. Ley K, Laudanna C, Cybulsky MI, Nourshargh S. Getting to the Site of Inflammation: The Leukocyte Adhesion Cascade Updated. Nat Rev Immunol (2007) 7:678-89. doi: 10.1038/nri2156

27. Voisin M-B, Nourshargh S. Neutrophil Transmigration: Emergence of an Adhesive Cascade Within Venular Walls. J Innate Immun (2013) 5:336-47. doi: $10.1159 / 000346659$

28. Berman CL, Yeo EL, Wencel-Drake JD, Furie BC, Ginsberg MH, Furie B. A Platelet Alpha Granule Membrane Protein That Is Associated With the Plasma Membrane After Activation. Characterization and Subcellular Localization of Platelet Activation-Dependent Granule-External Membrane Protein. J Clin Invest (1986) 78:130-7. doi: 10.1172/JCI112542

29. McEver RP, Beckstead JH, Moore KL, Marshall-Carlson L, Bainton DF. Gmp-140, A Platelet $\alpha$-Granule Membrane Protein, Is Also Synthesized by Vascular Endothelial Cells and Is Localized in Weibel-Palade Bodies. J Clin Invest (1989) 84:92-9. doi: 10.1172/JCI114175

30. Kansas GS. Selectins and Their Ligands: Current Concepts and Controversies. In: Blood. American Society of Hematology (1996). p. 3259-87. doi: 10.1182/blood.V88.9.3259.bloodjournal8893259

31. Zarbock A, Ley K, McEver RP, Hidalgo A. Leukocyte Ligands for Endothelial Selectins: Specialized Glycoconjugates That Mediate Rolling and Signaling Under Flow. Blood (2011) 118:6743-51. doi: 10.1182/blood-2011-07-343566

32. Spertini O, Cordey A, Monai N, Guiffre L, Schapira M. P-Selectin Glycoprotein Ligand 1 Is a Ligand for L-Selectin on Neutrophils, Monocytes, and CD34 + Hematopoietic Progenitor Cells. J Cell Biol (1996) 135(2):523-31. doi: 10.1083/jcb.135.2.523

33. Davenpeck KL, Brummet ME, Hudson SA, Mayer RJ, Bochner BS. Activation of Human Leukocytes Reduces Surface P-Selectin Glycoprotein Ligand-1 (Psgl-1, CD162) and Adhesion to P-Selectin In Vitro. J Immunol (2000) 165:2764-72. doi: 10.4049/jimmunol.165.5.2764

34. Alon R, Fuhlbrigge RC, Finger EB, Springer TA. Interactions Through Lselectin Between Leukocytes and Adherent Leukocytes Nucleate Rolling Adhesions on Selectins and VCAM-1 in Shear Flow. J Cell Biol (1996) 135:849-65. doi: 10.1083/jcb.135.3.849

35. Xu H, Manivannan A, Crane I, Dawson R, Liversidge J. Critical But Divergent Roles for CD62L and CD44 in Directing Blood Monocyte Trafficking In Vivo During Inflammation. Blood (2008) 112(4):116-1174. doi: 10.1182/blood-2007-06-098327

36. Gómez-Gaviro MV, Domínguez-Jiménez C, Carretero JM, Sabando P, González-Alvaro I, Sánchez-Madrid F. Down-Regulation of L-selectin Expression in Neutrophils by Nonsteroidal Anti-Inflammatory Drugs: Role of Intracellular ATP Concentration. Blood (2000) 96:3592-600. doi: 10.1182/blood.V96.10.3592

37. Zöllner O, Lenter MC, Blanks JE, Borges E, Steegmaier M, Zerwes HG, et al. L-Selectin From Human, But Not From Mouse Neutrophils Binds Directly to E-Selectin. J Cell Biol (1997) 136:707-16. doi: 10.1083/jcb.136.3.707

38. Martins PDC, García-Vallejo JJ, Van Thienen JV, Fernandez-Borja M, Van Gils JM, Beckers C, et al. P-Selectin Glycoprotein Ligand-1 Is Expressed on Endothelial Cells and Mediates Monocyte Adhesion to Activated Endothelium. Arteriosclerosis Thrombosis Vasc Biol (2007) 27:1023-9. doi: 10.1161/ATVBAHA.107.140442

39. Marshall BT, Long M, Piper JW, Yago T, McEver RP, Zhu C, et al. Direct Observation of Catch Bonds Involving Cell-Adhesion Molecules. Nature (2003) 423:190-3. doi: 10.1038/nature01605

40. Phillipson M, Heit B, Colarusso P, Liu L, Ballantyne CM, Kubes P. Intraluminal Crawling of Neutrophils to Emigration Sites: A Molecularly Distinct Process From Adhesion in the Recruitment Cascade. J Exp Med (2006) 203:2569-75. doi: 10.1084/jem.20060925

41. Choi EY, Santoso S, Chavakis T. Mechanisms of Neutrophil Transendothelial Migration. Front Biosci (2010) 14:1596-605. doi: 10.2741/3327

42. Gane J, Stockley R. Mechanisms of Neutrophil Transmigration Across the Vascular Endothelium in COPD. In: Thorax. BMJ Publishing Group Ltd (2012). p. 553-61. doi: 10.1136/thoraxjnl-2011-200088

43. Carman CV, Springer TA. A Transmigratory Cup in Leukocyte Diapedesis Both Through Individual Vascular Endothelial Cells and Between Them. J Cell Biol (2004) 167:377-88. doi: 10.1083/jcb.200404129

44. Kölsch V, Charest PG, Firtel RA. The Regulation of Cell Motility and Chemotaxis by Phospholipid Signaling. J Cell Sci (2008) 121:551-9. doi: $10.1242 /$ jcs. 023333
45. Hirsch E, Katanaev VL, Garlanda C, Azzolino O, Pirola L, Silengo L, et al. Central Role for G Protein-Coupled Phosphoinositide 3-Kinase Gamma in Inflammation. Science (2000) 287(5455):1049-53. doi: 10.1126/ science.287.5455.1049

46. Nick JA, Avdi NJ, Young SK, Knall C, Gerwins P, Johnson GL, et al. Common and Distinct Intracellular Signaling Pathways in Human Neutrophils Utilized by Platelet Activating Factor and FMLP. J Clin Invest (1997) 99:975-86. doi: 10.1172/JCI119263

47. Summers C, Singh NR, White JF, Mackenzie IM, Johnston A, Solanki C, et al. Pulmonary Retention of Primed Neutrophils: A Novel Protective Host Response, Which Is Impaired in the Acute Respiratory Distress Syndrome. Thorax (2014) 69:623-9. doi: 10.1136/thoraxjnl-2013-204742

48. Ekpenyong AE, Toepfner N, Fiddler C, Herbig M, Li W, Cojoc G, et al. Mechanical Deformation Induces Depolarization of Neutrophils. Sci Adv (2017) 3(6):e1602536. doi: 10.1126/sciadv.1602536

49. Aulakh GK. Monocyte Recruitment During Infection and Inflammation. Cell Tissue Res (2017) 371:577-88. doi: 10.1007/s00441-017-2748-z

50. Cepinskas G, Sandig M, Kvietys PR. PAF-Induced Elastase-Dependent Neutrophil Transendothelial Migration Is Associated With the Mobilization of Elastase to the Neutrophil Surface and Localization to the Migrating Front. J Cell Sci (1999) 112(12):1937-45. doi: 10.1242/ jcs.112.12.1937

51. Walmsley SR, Print C, Farahi N, Peyssonnaux C, Johnson RS, Crammer T, et al. Hypoxia-Induced Neutrophil Survival Is Mediated by HIF-1 $\alpha-$ Dependent NF-kb Activity. J Exp Med (2005) 201(1):105-15. doi: 10.1084/ jem.20040624

52. Aulakh GK. Neutrophils in the Lung: "The First Responders". Cell Tissue Res (2017) 371:577-88. doi: 10.1007/s00441-017-2748-z

53. Belchamber KBR, Donnelly LE. Macrophage Function in Respiratory Disease. In: Macrophages: Origin, Functions and Biointervention. M Kloc, editor. Springer (2017) p. 299-313. doi: 10.1007/978-3-319-54090-0_12

54. Greenlee-Wacker MC. Clearance of Apoptotic Neutrophils and Resolution of Inflammation. Immunol Rev (2016) 273:357-70. doi: 10.1111/imr.12453

55. Gabelloni ML, Trevani AS, Sabatte J, Geffner J. Mechanisms Regulating Neutrophil Survival and Cell Death. Semin Immunopathol (2013) 35:423-7. doi: 10.1007/s00281-013-0364-x

56. Bustamante-Marin XM, Ostrowski LE. Cilia and Mucociliary Clearance. Cold Spring Harbour Perspect Biol (2017) 9(4):a028241. doi: 10.1101/ cshperspect.a028241

57. Singh D, Edwards L, Tal-Singer R, Rennard SI. Sputum Neutrophils as a Biomarker in COPD: Findings From the ECLIPSE Study. Respir Res (2010) 11(1). doi: 10.1186/1465-9921-11-77

58. Beeh KM, Beir J, Kornmann O, Buhl R. Neutrophilic Inflammation in Induced Sputum of Patients With Idiopathic Pulmonary Fibrosis. Sarcoidosis Vasc Diffuse Lung Dis (2003) 20(2):138-43.

59. de Oliviera S, Rosowski EE, Huttenlocher A. Neutrophil Migration in Infection and Wound Repair: Going Forward in Reverse. Nat Rev Immunol (2016) 16:378-91. doi: 10.1038/nri.2016.49

60. Musher DM, Haque-Park M, Baughn RE, Wallace RJ, Cowley B. Opsonizing and Bacteriocidal Effects of Normal Human Serum on Nontypeable Haemophilus Influenzae. Infect Immun (1983) 39:297-304. doi: 10.1128/ iai.39.1.297-304.1983

61. Brezski RJ, Jordan RE. Cleavage of IgGs by Proteases Associated With Invasive Diseases: An Evasion Tactic Against Host Immunity? mAbs (2010) 2(3):212-20. doi: 10.4161/mabs.2.3.11780

62. Tosi MF, Zakem H, Berger M. Neutrophil Elastase Cleaves C3bi on Opsonised Pseudomonas as Well as CR1 on Neutrophils to Create a Functionally Important Opsonin Receptor Mismatch. J Clin Invest (1990) 86:300-8. doi: 10.1172/JCI114699

63. Shibata Y, Berclaz P, Chroneos ZC, Yoshida M, Whitsett JA, Trapnells BC. Gm-Csf Regulates Alveolar Macrophage Differentiation and Innate Immunity in the Lung Through PU.1. Immunity (2001) 15(4):557-67. doi: 10.1016/S1074-7613(01)00218-7

64. Cook PC, MacDonald AS. Dendritic Cells in Lung Immunopathology. Semin Immunopathol (2016) 38(4):449-60. doi: 10.1007/s00281-016-0571-3

65. Kielty CM, Sherratt MJ, Shuttleworth A. Elastic Fibres. J Cell Sci (2002) 115 (14):2817-28. doi: 10.1242/jcs.115.14.2817 
66. Laurent P, Janoff A, Kagan HM. Cigarette Smoke Blocks Cross-Linking of Elastin In Vitro. Am Rev Respir Dis (1983) 127(2):189-92. doi: 10.1164/ arrd.1983.127.2.189

67. Snell N, Strachan D, Hubbard RB, Gibson J, Limb E, Gupta R, et al. Burden of Lung Disease in the UK; Findings From the British Lung Foundation's 'Respiratory Health of the Nation' Project. Eur Respir J (2016) 48. doi: 10.1183/13993003.congress-2016.PA4913

68. England PH. Surveillance of Influenza and Other Respiratory Viruses in the UK, P.H. England, Editor. London SE1 8UG: PHE publications (2020). Available at: https://assets.publishing.service.gov.uk/government/ uploads/system/uploads/attachment_data/file/895233/Surveillance_ Influenza_and_other_respiratory_viruses_in_the_UK_2019_to_2020_ FINAL.pdf.

69. Coronavirus (COVID-19) Roundup. Available at: https://www.ons.gov.uk/ peoplepopulationandcommunity/healthandsocialcare/conditionsanddiseases/ articles/coronaviruscovid19roundup/2020-03-26.

70. Deaths from asthma and Chronic Obstructive Pulmonary Disease by age group. England and Wales, 2001 to 2017, O.f.N. Statistics, Editor. Newport, Gwent: Office for National Statistics (2019).

71. Navartnam V, Hubbard RB. The Mortality Burden of Idiopathic Pulmonary Fibrosis in the United Kingdom. Am J Respir Crit Care Med (2019) 200 (2):256-8. doi: 10.1164/rccm.201902-0467LE

72. Kronenberg RS, Drage CW. Attenuation of the Ventilatory and Heart Rate Responses to Hypoxia and Hypercapnia With Aging in Normal Men. J Clin Invest (1973) 52(8):1812-9. doi: 10.1172/JCI107363

73. Albright JM, Dunn RC, Shults JA, Boe DM, Afshar M, Kovacs EJ. Advanced Age Alters Monocyte and Macrophage Responses. Antioxid Redox Signalling (2016) 25(15):805-15. doi: 10.1089/ars.2016.6691

74. Niwa Y, Kasama T, Miyachi Y, Kanoh T. Neutrophil Chemotaxis, Phagocytosis and Parameters of Reactive Oxygen Species in Human Aging: Cross-Sectional and Longitudinal Studies. Life Sci (1989) 44 (22):1655-64. doi: 10.1016/0024-3205(89)90482-7

75. Fulop T, Larbi A, Douziech N, Fortin C, Guerard K, Lesur O, et al. Signal Transduction and Functional Changes in Neutrophils With Aging. Aging Cell (2004) 3(4). doi: 10.1111/j.1474-9728.2004.00110.x

76. Wilson D, Drew W, Jasper A, Crisford H, Nightingale P, Newby P, et al. Frailty Is Associated With Neutrophil Dysfunction Which Is Correctable With Phosphoinositol-3-Kinase Inhibitors. J Gerentol (2020) 75(12):2320-5. doi: $10.1093 /$ gerona/glaa216

77. Sapey E, Greenwood H, Walton G, Mann E, Love A, Aaronson N, et al. Phosphoinositide 3-Kinase Inhibition Restores Neutrophil Accuracy in the Elderly: Toward Targeted Treatments for Immunosenescence. Blood (2014) 123:239-48. doi: 10.1182/blood-2013-08-519520

78. Keller HU, Wissler JH, Hess MW, Cottier H. Distinct Chemokinetic and Chemotactic Responses in Neutrophil Granulocytes. Eur J Immunol (1978) 8:1-7. doi: 10.1002/eji.1830080102

79. Lord JM, Butcher S, Killampali V, Lascelles D, Salmon M. Neutrophil Ageing and Immunosenescence. Mechansms Ageing Dev (2001) 122(14):1521-35. doi: 10.1016/S0047-6374(01)00285-8

80. Wenisch C, Patruta S, Daxbock F, Krause R, Horl W. Effect of Age on Human Neutrophil Function. J Leukocyte Biol (2000) 67(1):40-5. doi: 10.1002/jlb.67.1.40

81. Hearps AC, Martin GE, Angelovich TA, Cheng W-J, Maisa A, Landay AL, et al. Aging Is Associated With Chronic Innate Immune Activation and Dysregulation of Monocyte Phenotype and Function. Aging Cell (2012) 11 (5):867-75. doi: 10.1111/j.1474-9726.2012.00851.x

82. Nyugen J, Agrawal S, Gollapudi S, Gupta S. Impaired Functions of Peripheral Blood Monocyte Subpopulations in Aged Humans. J Clin Immunol (2010) 30(6):806-13. doi: 10.1007/s10875-010-9448-8

83. Metcalf TU, Cubas RA, Ghneim K, Cartwright MJ, Grevenynghe JV, Richner JM, et al. Global Analyses Revealed Age-Related Alterations in Innate Immune Responses After Stimulation of Pathogen Recognition Receptors. Aging Cell (2015) 14(3):421-32. doi: 10.1111/acel.12320

84. Metcalf TU, Wilkinson PA, Cameron MJ, Ghneim K, Chiang C, Wertheimer AM, et al. Human Monocyte Subsets Are Transcriptionally and Functionally Altered in Aging in Response to Pattern Recognition Receptor Agonists. J Immunol (2017) 199(4):1405-17. doi: 10.4049/ jimmunol.1700148
85. Nyugen J, Agrawal S, Gollapudi S, Gupta S. Impaired Functions of Peripheral Blood Monocyte Subpopulations in Aged Humans. J Clin Immunol (2010) 30(6):806-13. doi: 10.1007/s10875-010-9448-8

86. Samson LD, Boots AMH, Verschuren WMM, Picavet HSJ, Engelfriet P, Buisman AM. Frailty Is Associated With Elevated CRP Trajectories and Higher Numbers of Neutrophils and Monocytes. Exp Gerontol (2019) 125:110674. doi: 10.1016/j.exger.2019.110674

87. Saare M, Tserel L, Haljasmägi L, Taalberg E, Peet N, Eimre M, et al. Monocytes Present Age-Related Changes in Phospholipid Concentration and Decreased Energy Metabolism. Aging Cell (2020) 19(4):e13127. doi: 10.1111/acel.13127

88. GOLD Report in Global Strategy for the Diagnosis. Management, and Prevention of Chronic Obstructive Pulmonary Disease. AG Agusti, C Vogelmeier, editors (2020). doi: 10.1164/rccm.201204-0596PP

89. Barnes PJ. Mediators of Chronic Obstructive Pulmonary Disease. Pharmacol Rev (2004) 56(4):515-48. doi: 10.1124/pr.56.4.2

90. Retamales I, Elliott WM, Meshi B, Coxson HO, Pare PD, Sciurba FC, et al. Amplification of Inflammation in Emphysema and Its Association With Latent Adenoviral Infection. Am J Respir Crit Care Med (2001) 164(3):46973. doi: 10.1164/ajrccm.164.3.2007149

91. Pérez-Rial S, Puerto-Nevado LD, Terrón-Expósito R, Girón-Martínez Á, González-Mangado N, Peces-Barba G. Role of Recently Migrated Monocytes in Cigarette Smoke-Induced Lung Inflammation in Different Strain of Mice. PloS One (2013) 8(9):e72975. doi: 10.1371/journal.pone.0072975

92. Cai Y, Sugimoto C, Arainga M, Alvarez X, Didier ES, Kuroda MJ. In Vivo Characterization of Alveolar and Interstitial Lung Macrophages in Rhesus Macaques: Implications for Understanding Lung Disease in Humans. J Immunol (2014) 192(6):2821-9. doi: 10.4049/jimmunol.1302269

93. Keatings VM, Collins PD, Scott DM, Barnes PJ. Differences in Interleukin-8 and Tumor Necrosis Factor- $\alpha$ in Induced Sputum From Patients With Chronic Obstructive Pulmonary Disease or Asthma. Am J Respir Crit Care Med (1996) 153:530-4. doi: 10.1164/ajrccm.153.2.8564092

94. Sapey E, Bayley D, Ahmad A, Newbold P, Snell N, Stockley RA. InterRelationships Between Inflammatory Markers in Patients With Stable COPD With Bronchitis: Intra-Patient and Inter-Patient Variability. Thorax (2008) 63(6):493-9. doi: 10.1136/thx.2007.086751

95. Stone H, McNab G, Wood AM, Stockley RA, Sapey E. Variability of Sputum Inflammatory Mediators in COPD and alpha1-antitrypsin Deficiency. Eur Respir J (2012) 40(3):561-9. doi: 10.1183/09031936.00162811

96. Traves SL, Culpitt SV, Russell RE, Barnes PJ, Donnelly LE. Elevated Levels of the Chemokines GRO and MCP-1 in Sputum Samples From COPD Patients. Thorax (2002) 57:586-9. doi: 10.1136/thorax.57.7.590

97. Sapey E, Stockley JA, Greenwood H, Ahmad A, Bayley D, Lord JM, et al. Behavioral and Structural Differences in Migrating Peripheral Neutrophils From Patients With Chronic Obstructive Pulmonary Disease. Am J Respir Crit Care Med (2011) 183(9):1176-86. doi: 10.1164/rccm.201008-1285OC

98. Yip KP, Hughes M, Stockley R, Sapey E. S70 Inaccurate Neutrophil Migration in Symptomatic Smokers Without Chronic Obstructive Pulmonary Disease. Thorax (2019) 74(Suppl 2):A46. doi: 10.1136/thorax2019-BTSabstracts2019.76

99. Kato A, Hanaoka M. Pathogenesis of COPD (Persistence of Airway Inflammation): Why Does Airway Inflammation Persist After Cessation of Smoking?, In: Chronic Obstructive Pulmonary Disease: A Systemic Inflammatory Disease. H Nakamura, K Aoshiba, editors. Singapore: Springer Singapore (2017) p. 57-72.

100. Costa C, Rufino R, Traves SL, Lapa ES JR, Barnes PJ, Donnelly LE. CXCR3 and CCR5 Chemokines in Induced Sputum From Patients With COPD. Chest (2008) 133(1):26-33. doi: 10.1378/chest.07-0393

101. Aldonyte R, Jansson L, Piitulainen E, Janciauskiene S. Circulating Monocytes From Healthy Individuals and COPD Patients. Respir Res (2003) 4(1). doi: 10.1186/1465-9921-4-11

102. Taylor AE, Finney-Hayward TK, Quint JK, Thomas CM, Tudhope SJ, Wedzicha JA, et al. Defective Macrophage Phagocytosis of Bacteria in COPD. Eur Respir J (2010) 35(5):1039-47. doi: 10.1183/09031936.00036709

103. Wrench C, Belchamber KBR, Bercusson A, Shah A, Barnes PJ, Donnelly LE. Reduced Clearance of Fungal Spores by COPD Gm-CSF and M-CSF Derived Macrophages. Am J Respir Cell Mol Biol (2018) 58(2):271-3. doi: 10.1165/ rcmb.2017-0351LE 
104. Belchamber KBR, Singh R, Batista CM, Whyte MK, Dockrell DH, Kilty I, et al. Defective Bacterial Phagocytosis Is Associated With Dysfunctional Mitochondria in COPD. Eur Respir J (2019) 54(3):1802244. doi: 10.1183/13993003.02244-2018

105. Desai O, Winkler J, Minasyan M, Herzog EL, et al. The Role of Immune and Inflammatory Cells in Idiopathic Pulmonary Fibrosis. Front Med (2018). doi: 10.3389/fmed.2018.00043

106. Leslie J, Millar BJ, Del Carpio Pons A, Burgoyne RA, Frost JD, Barksby BS. FPR-1 Is an Important Regulator of Neutrophil Recruitment and a TissueSpecific Driver of Pulmonary Fibrosis. JCI Insight (2020) 5(4):e125937. doi: 10.1172/jci.insight.125937

107. Molyneaux PL, Maher TM. The Role of Infection in the Pathogenesis of Idiopathic Pulmonary Fibrosis. Eur Respir Rev (2013) 22(129):376. doi: $10.1183 / 09059180.00000713$

108. Byrne AJ, Maher TM, Lloyd CM. Pulmonary Macrophages: A New Therapeutic Pathway in Fibrosing Lung Disease? Trends Mol Med (2016) 22(4):303-16. doi: 10.1016/j.molmed.2016.02.004

109. Scott MKD, Quinn K, Li Q, Carroll R, Warsinske H, Vallania F, et al. Increased Monocyte Count as a Cellular Biomarker for Poor Outcomes in Fibrotic Diseases: A Retrospective, Multicentre Cohort Study. Lancet Respir Med (2019) 7(6):497-508. doi: 10.1016/S2213-2600(18)30508-3

110. Sapey E, Patel JM, Greenwood HL, Walton GM, Hazeldine J, Sadhra C. Pulmonary Infections in the Elderly Lead to Impaired Neutrophil Targeting, Which Is Improved by Simvastatin. Am J Respir Crit Care Med (2017) 196 (10):1325-36. doi: 10.1164/rccm.201704-0814OC

111. Patel JM, Sapey E, Parekh D, Scott A, Dosanjh D, Gao F, et al. Sepsis Induces a Dysregulated Neutrophil Phenotype That Is Associated With Increased Mortality. Mediators Inflammation (2018) 2018:4065362. doi: 10.1155/2018/ 4065362

112. Sapey E, Patel JM, Greenwood H, Walton GM, Grudzinska F, Parekh D, et al. Simvastatin Improves Neutrophil Function and Clinical Outcomes in Pneumonia: A Pilot Randomised Controlled Trial. Am J Respir Crit Care Med (2019) 200:1282-93. doi: 10.1164/rccm.201812-2328OC

113. Rennard SI, Fogarty C, Kelsen S, Long W, Ramsdell J, Allison J, et al. The Safety and Efficacy of Infliximab in Moderate to Severe Chronic Obstructive Pulmonary Disease. Am J Respir Crit Care Med (2007) 175(9):926-34. doi: 10.1074/jbc.273.17.10095

114. Aaron SD, Vandemheen KL, Maltais F, Field SK, Sin DD, Bourbeau J, et al. Nf $\alpha$ Antagonists for Acute Exacerbations of COPD: A Randomised Double-Blind Controlled Trial. Thorax (2012) 68:142-8. doi: 10.1136/thoraxjnl-2012-202432

115. Gompertz S, Stockley RA, Randomized A. Placebo-Controlled Trial of a Leukotriene Synthesis Inhibitor in Patients With Copd. Chest (2002) 122 (1):289-94. doi: 10.1378/chest.122.1.289

116. Lazaar AL, Miller BE, Donald AC, Keeley T, Ambery C, Russell J. CXCR2 Antagonist for Patients With Chronic Obstructive Pulmonary Disease With Chronic Mucus Hypersecretion: A Phase 2b Trial. Respir Res (2020) 21:149. doi: $10.1189 / \mathrm{jlb} .0805458$

117. Kuna P, Jenkins M, O’Brien CD, Fahy WA. AZD9668, a Neutrophil Elastase Inhibitor, Plus Ongoing Budesonide/Formoterol in Patients With COPD. Respir Med (2012) 106(4):531-9. doi: 10.1016/j.rmed.2011.10.020

118. Stockley RA, A DS, Gunawardena K, Perrett J, Forsman-Semb N, Entwistle N, et al. Phase II Study of a Neutrophil Elastase Inhibitor (AZD9668) in Patients With Bronchiectasis. Respir Med (2013) 107(4):524-33. doi: 10.1016/j.rmed.2012.12.009

119. Alflen A, Stadler N, Lopez PA, Teschner D, Theobald M, Hes G. Idelalisib Impairs TREM-1 Mediated Neutrophil Inflammatory Responses. Sci Rep (2018) 8(1):5558. doi: 10.1038/s41598-018-23808-2

120. White JR, Lee JM, Young PR, Hertzberg RP, Jurewicz AJ, Chaikin MA. Identification of a Potent, Selective Non-Peptide CXCR2 Antagonist That Inhibits Interleukin-8-Induced Neutrophil Migration. J Biol Chem (1998) 273:10095-8. doi: 10.1074/jbc.273.17.10095

121. Stevenson CS, Coote K, Webster R, Johnston H, Atherton HC, Nicholls A, et al. Characterization of Cigarette Smoke-Induced Inflammatory and Mucus Hypersecretory Changes in Rat Lung and the Role of CXCR2 Ligands in Mediating This Effect. Am J Physiol-Lung Cell Mol Physiol (2005) 288:L51422. doi: 10.1152/ajplung.00317.2004

122. Lomas-Neira JL, Chung C-S, Grutkoski PS, Miller EJ, Ayala A, et al. CXCR2 Inhibition Suppresses Hemorrhage-Induced Priming for Acute Lung Injury in Mice. J Leukocyte Biol (2004) 76:58-64. doi: 10.1189/jlb.1103541
123. Gordon JR. The Combined CXCR1/CXCR2 Antagonist CXCL8(3-74)K11R/ G31P Blocks Neutrophil Infiltration, Pyrexia, and Pulmonary Vascular Pathology in Endotoxemic Animals. J Leukocyte Biol (2005) 78:1265-72. doi: $10.1189 / \mathrm{jlb} .0805458$

124. Aaron SD. Walking a Tightrope: Targeting Neutrophils to Treat Chronic Obstructive Pulmonary Disease. In: American Journal of Respiratory and Critical Care Medicine. American Thoracic Society (2015). p. 971-2. doi: 10.1189/jlb.3A0916-388RR

125. Crooks SW, Bayley DL, Hill SL, Stockley RA. Bronchial Inflammation in Acute Bacterial Exacerbations of Chronic Bronchitis: The Role of Leukotriene B4. Eur Respir J (2000) 15(2):274-80. doi: 10.1034/j.13993003.2000.15b09.x

126. Bracke KR, D'hulst AI, Maes T, Moerloose KB, Demedts IK, Lebecque S, et al. Cigarette Smoke-Induced Pulmonary Inflammation and Emphysema Are Attenuated in CCR6-Deficient Mice. J Immunol (2006) 177(7):4350-9. doi: 10.4049/jimmunol.177.7.4350

127. Nie L, Liu Z, Xiang R, CXiao Y, Lu B, Pang B, et al. Chemokine Receptor CXCR3 Is Important for Lung Tissue Damage and Airway Remodeling Induced by Short-Term Exposure to Cigarette Smoking in Mice. Acta Pharmacol Sin (2010) 31(4):436-42. doi: 10.1038/aps.2009.192

128. Ma B, Kang M, Lee CG, Chapoval S, Liu W, Chen Q, et al. Role of CCR5 in IFN- $\gamma$-Induced and Cigarette Smoke-Induced Emphysema. J Clin Invest (2005) 115(12):3460-72. doi: 10.1172/JCI24858

129. Silveira AAA, Dominical VM, Almeida CB, Chweih H, Ferreira WA Jr, Vicente CP. TNF Induces Neutrophil Adhesion Via Formin-Dependent Cytoskeletal Reorganization and Activation of $\beta$-Integrin Function. J Leukoc Biol (2018) 103(1):87-98. doi: 10.1016/s0955-0674(02)00311-3

130. Lauterbach M, O'Donnell P, Asano K, Mayadas TN. Role of TNF Priming and Adhesion Molecules in Neutrophil Recruitment to Intravascular Immune Complexes. J Leukoc Biol (2008) 83(6):1423-30. doi: 10.1189/jlb.0607421

131. Sapey E, Ahmad A, Bayley D, Newbold P, Snell N, Rugman P. Imbalances Between Interleukin-1 and Tumor Necrosis Factor Agonists and Antagonists in Stable COPD. J Clin Immunol (2009) 29(4):508-16. doi: 10.1007/s10875009-9286-8

132. Stephens L, Ellson C, Hawkins P. Roles of PI3Ks in Leukocyte Chemotaxis and Phagocytosis. Curr Opin Cell Biol (2002) 14(2):203-13. doi: 10.1016/ S0955-0674(02)00311-3

133. Medina-Tato DA, Ward SG, Watson ML. Phosphoinositide 3-Kinase Signalling in Lung Disease: Leucocytes and Beyond. Immunology (2007) 121(4):448-61. doi: 10.1111/j.1365-2567.2007.02663.x

134. Stephens L, Ellson C, Hawkins P. Roles of PI3Ks in Leukocyte Chemotaxis and Phagocytosis. Curr Opin Cell Biol (2002) 14(2):203-13. doi: 10.1016/ S0955-0674(02)00311-3

135. Hessel E, Hamblin JN, Robertson J, Begg M, Jarvis E, Wilson R, et al. Inhaled Pi3k $\delta$ Inhibitor Nemiralisib Improves Lung Function and Reduces ReExacerbations in Exacerbating Chronic Obstructive Pulmonary Disease (Copd) Patients (PII116678), in D12. In: Immunotherapy IN Lung Disease. American Thoracic Society (2018). p. A6169-9.

136. Yang J, Liu C, Zhang L, Liu Y, Guo A, Shi H, et al. Intensive Atorvastatin Therapy Attenuates the Inflammatory Responses in Monocytes of Patients With Unstable Angina Undergoing Percutaneous Coronary Intervention Via Peroxisome Proliferator-Activated Receptor $\gamma$ Activation. Inflammation (2015) 38(4):1415-23. doi: 10.1007/s10753-015-0116-2

137. Toribio M, Fitch KV, Sanchez L, Burdo TH, Williams KC, Sponseller CA, et al. Effects of Pitavastatin and Pravastatin on Markers of Immune Activation and Arterial Inflammation in HIV. Aids (2017) 31(6):797-806. doi: 10.1097/QAD.0000000000001427

138. Grudzinska FS, Dosanjh DPS, Parekh D, Dancer RCA, Patel J, Nightingale P, et al. Statin Therapy in Patients With Community-Acquired Pneumonia. Clin Med (2017) 17(5):403-7. doi: 10.7861/clinmedicine.17-5-403

139. Greenwood H, Patel J, Mahida R, Wang Q, Parekh D, Dancer RC. Simvastatin to Modify Neutrophil Function in Older Patients With Septic Pneumonia (SNOOPI): Study Protocol for a Randomised PlaceboControlled Trial. Trials (2014) 15:332. doi: 10.1186/1745-6215-15-332

140. Sapey E, Patel JM, Greenwood H, Walton G, Grudzinska F, Parekh D, et al. Simvastatin Improves Neutrophil Function and Clinical Outcomes in Pneumonia. A Pilot Randomized Controlled Clinical Trial. Am J Respir Crit Care Med (2019) 200(10):1282-93. doi: 10.1164/rccm.201812-2328OC 
141. Rosuvastatin for Sepsis-Associated Acute Respiratory Distress Syndrome. N Engl J Med (2014) 370(23):2191-200. doi: 10.1056/NEJMoa1401520

142. Calfee CS, Delucchi KL, Sinha P, Matthay MA, Hackett J, Shankar-Hari M. Acute Respiratory Distress Syndrome Subphenotypes and Differential Response to Simvastatin: Secondary Analysis of a Randomised Controlled Trial. Lancet Resir Med (2018) 6(9):691-8. doi: 10.1016/S2213-2600(18) 30177-2

143. Walton G, Stockley JA, Griffiths D, Sadhra CS, Purvis T, Sapey E. Repurposing Treatments to Enhance Innate Immunity. Can Statins Improve Neutrophil Functions and Clinical Outcomes in COPD? J Clin Med (2016) 5(10):89. doi: 10.3390/jcm5100089

144. Lu Y, Chang R, Yao J, Xu X, Teng Y, Cheng N, et al. Effectiveness of LongTerm Using Statins in COPD - A Network Meta-Analysis. Respir Res (2019) 20(1):17. doi: 10.1186/s12931-019-0984-3

145. Howard ML, Vincent AH. Statin Effects on Exacerbation Rates, Mortality, and Inflammatory Markers in Patients With Chronic Obstructive Pulmonary Disease: A Review of Prospective Studies. Pharmacotherapy (2016) 36(5):536-47. doi: 10.1002/phar.1740

146. Polverino E, Rosales-Mayor E, Dale GE, Dembowsky K, Torres A, et al. The Role of Neutrophil Elastase Inhibitors in Lung Diseases. Chest (2017) 152 (2):249-62. doi: 10.1016/j.chest.2017.03.056

147. Chapman KR, Burdon JGW, Piitulainen E, Sandhaus RA, Seersholm N, Stocks JM. Intravenous Augmentation Treatment and Lung Density in Severe $\alpha 1$ Antitrypsin Deficiency (RAPID): A Randomised, Double-Blind, Placebo-Controlled Trial. Lancet (2015) 386(9991):360-8. doi: 10.1016/ S0140-6736(15)60860-1

148. Hurley K, Lacey N, O'Dwyer CA, Bergin DA, McElvaney OJ, O'Brien ME. Alpha-1 Antitrypsin Augmentation Therapy Corrects Accelerated
Neutrophil Apoptosis in Deficient Individuals. J Immunol (2014) 193 (8):3978. doi: 10.4049/jimmunol.1400132

149. Stockley JA, Stockley RA, Sapey E. There Is No Fast Track to Identify Fast Decliners in Alpha-1 Antitrypsin Deficiency by Spirometry: A Longitudinal Study of Repeated Measurements. Int J Chron Obstruct Pulmon Dis (2021) 16:835-40. doi: 10.2147/COPD.S298585

150. Chalmers JD, Haworth CS, Metersky ML, Loebinger MR, Blasi F, Sibila O. Phase 2 Trial of the DPP-1 Inhibitor Brensocatib in Bronchiectasis. N Engl J Med (2020) 383(22):2127-37. doi: 10.1056/NEJMoa2021713

151. Sapey E, Wood AM, Ahmad A, Stockley RA. Tumor Necrosis Factor-\{Alpha\} rs361525 Polymorphism Is Associated With Increased Local Production and Downstream Inflammation in Chronic Obstructive Pulmonary Disease. Am J Respir Crit Care Med (2010) 182(2):192-9. doi: 10.1164/rccm.200912-1846OC

152. Patel JM, Thickett DR, Gao F, Sapey E. Statins for Sepsis: Distinguishing Signal From the Noise When Designing Clinical Trials. Am J Respir Crit Care Med (2013) 188(7):874. doi: 10.1164/rccm.201302-0392LE

Conflict of Interest: The authors declare that the research was conducted in the absence of any commercial or financial relationships that could be construed as a potential conflict of interest.

Copyright $\odot 2021$ Belchamber, Hughes, Spittle, Walker and Sapey. This is an openaccess article distributed under the terms of the Creative Commons Attribution License (CC BY). The use, distribution or reproduction in other forums is permitted, provided the original author(s) and the copyright owner(s) are credited and that the original publication in this journal is cited, in accordance with accepted academic practice. No use, distribution or reproduction is permitted which does not comply with these terms. 